\title{
Flora epifítica vascular em três unidades vegetacionais do Rio Tibagi, Paraná, Brasil
}

\author{
Vascular epiphytic flora in three vegetacional units of the Tibagi River, Paraná, Brazil
}

\author{
Annete Bonnet ${ }^{1}$, Gustavo Ribas Curcio ${ }^{2}$, Osmir José Lavoranti ${ }^{2}$ \& Franklin Galvão ${ }^{3}$
}

\begin{abstract}
Resumo
Este trabalho teve como objetivo avaliar a composição florística dos epífitos vasculares ao longo do rio Tibagi, Paraná, em 23 áreas distribuídas em distintas altitudes, tipos climáticos e unidades vegetacionais. Foram analisadas as características ecológicas e a distribuição das espécies ao longo do gradiente estabelecido de montante para jusante do rio. Os epífitos vasculares foram representados por 188 espécies, pertencentes principalmente às famílias Orchidaceae, Polypodiaceae e Bromeliaceae e ao grupo dos holoepífitos característicos. As comunidades epifíticas do rio Tibagi foram enquadradas, de montante para jusante do rio, em duas unidades vegetacionais, floresta ombrófila mista e floresta estacional semidecidual, e na transição entre ambas, o ecótono. Estas apresentam distintas riquezas e composições florísticas, o que ressalta sua importância na conservação e manutenção da diversidade de epífitos no estado do Paraná. A vegetação do ecótono, situada na porção intermediária do rio, apresentou maior riqueza epifítica, o que se deve, provavelmente, ao contato entre as unidades vegetacionais, ao bom estado de conservação das florestas e à presença de corredeiras e cachoeiras.
\end{abstract}

Palavras-chave: heterogeneidade ambiental, planície, ecótono, Orchidaceae.

\begin{abstract}
The aim of this work was to evaluate the floristic composition of vascular epiphytes along the Tibagi River forests, Paraná, in 23 study areas distributed at different altitudes, climatic types and vegetacional units. The ecological characteristics and distribution of the species were analyzed along the gradient established from upstream to downstream. The vascular epiphytes were represented by 188 species, belonging mainly to Orchidaceae, Polypodiaceae and Bromeliaceae and to the characteristic holoepiphytes group. The epiphytic communities of Tibagi River were segmented, from upstream to downstream, in two vegetacional units, mixed ombrophillous forest and semidecidual seasonal forest, and in the transition between both, the ecotone. These segments have distinct richness and floristic composition, what emphasize the importance to conservation and maintenance of epiphytic diversity at Paraná state. The ecotonal vegetation, situated in the medium segment of the river, presented the major epiphytic richness, which is associated, probably, to the contact of the vegetacional units, to the good conservation status of the forests and the presence of rapids and waterfalls. Key words: environment heterogeneity, floodplain, ecotone, Orchidaceae.
\end{abstract}

\section{Introdução}

Epífitos são vegetais que utilizam outras plantas como suporte durante todo ou parte do seu ciclo de vida. O epifitismo existe em 83 diferentes famílias de plantas vasculares, o que representa aproximadamente $10 \%$ de toda a flora vascular descrita. No entanto, poucas famílias concentram grande parte das espécies, como Orchidaceae, Araceae, Bromeliaceae e Polypodiaceae (Gentry \& Dodson 1987). Orchidaceae, mais do que qualquer outra, obteve sucesso na colonização de fustes e ramos de

Este artigo possui material adicional em sua versão eletrônica.

\footnotetext{
${ }^{1}$ Bolsista do CNPq, Av. Paraná, 642, Bloco A, Apto 151, 80035-130, Curitiba, PR. Autor para correspondência: a_bonnet@hotmail.com

${ }^{2}$ Embrapa Florestas, Estrada da Ribeira, km 111, C. P. 319, 83411-000, Colombo, PR.

${ }^{3}$ UFPR, Depto. Ciências Florestais, Av. Prefeito Lothário Meissner, 632, Jardim Botânico, 80210-170, Curitiba, PR.
} 
árvores, com aproximadamente $70 \%$ da família adaptada ao ambiente epifítico (Benzing 1990).

Os levantamentos florísticos apontam que as plantas epifíticas são responsáveis por grande parcela da diversidade em ambientes tropicais, podendo constituir até $50 \%$ do total da flora vascular em algumas florestas (Benzing 1990). No Brasil, estudos registraram elevado número de espécies, como Fontoura et al. (1997), que relacionaram 293 espécies de epífitos na floresta ombrófila densa da Reserva Ecológica de Macaé de Cima (RJ), Kersten \& Kunyioshi (2006) que coletaram 208 espécies na floresta ombrófila mista do alto rio Iguaçu (PR), e Breier (2005), que registrou 175 espécies na floresta de restinga do Parque Estadual Ilha do Cardoso (SP).

Em ambientes fluviais, os poucos levantamentos de epífitos vasculares são na sua maioria pontuais (Silva et al. 1997; Dittrich et al. 1999; Rogalski \& Zanin 2003; Giongo \& Waechter 2004). Estudos mais amplos foram realizados nas planícies do rio Iguaçu, estado do Paraná (Kersten \& Kunyioshi 2006), revelando elevada riqueza e padrões de distribuição relacionados a variáveis ambientais específicas.

$\mathrm{O}$ rio Tibagi, com cerca de $550 \mathrm{~km}$ de extensão (Maack 2002), percorre o estado do Paraná no sentido sul-norte, sendo acompanhado pela floresta ombrófila mista (FOM), a partir das nascentes, e pela floresta estacional semidecidual (FES), no trecho mais próximo à região do seu deságüe no rio Paranapanema. Devido à influência da tectônica do arco de Ponta Grossa, o rio Tibagi possui paisagens muito distintas ao longo do seu curso. Ocorrem mudanças nos padrões de leito do rio e nas feições geomorfológicas formadoras das margens, alternando-se planícies muito largas e diversos segmentos meândricos do rio com cânions, vales estreitos, presença de cachoeiras e encostas com muitos afloramentos rochosos. Estas paisagens singulares, associadas com distintos tipos climáticos, possibilitam a existência de hábitats diversos para o componente epifítico.

Com base no domínio das unidades vegetacionais que se sucedem ao longo do rio, FOM e FES, e da região de transição entre elas, o trabalho teve como objetivo avaliar a flora epifítica vascular nas florestas que margeiam o rio Tibagi, analisando suas características ecológicas e sua distribuição espacial.

\section{Material e Métodos}

\section{Áreas de estudo}

O estudo foi realizado no período de 20062008, ao longo do rio Tibagi, desde as suas nascentes, no município de Ponta Grossa (PR), até próximo a sua foz, na região de Londrina (PR), entre as coordenadas geográficas $23^{\circ} 18^{\prime}-26^{\circ} 17^{\prime} \mathrm{S}$ e 49 $59^{\prime}-50^{\circ} 58^{\prime} \mathrm{W}$. Para levantamento florístico, foram estabelecidas 23 áreas de estudo, distribuídas de montante para jusante do rio (Fig. 1), segundo cotas altimétricas, características geomorfológicas, climáticas, pedológicas e vegetacionais.

As nove primeiras áreas de estudo (1-9), de montante para jusante do rio (Fig. 1), estão inseridas na região de predomínio do tipo climático $\mathrm{Cfb}$ da classificação de Köppen, com verões frescos, invernos rigorosos, ocorrência freqüente de geadas e sem estação seca definida (IAPAR 2008). De acordo com uma série de 31 anos de dados climáticos (1974 2004), a temperatura média do mês mais frio nessa região foi $10,9^{\circ} \mathrm{C}$ e do mês mais quente $23,2^{\circ} \mathrm{C}$. No mesmo período, a precipitação média anual registrada foi $1.609 \mathrm{~mm} / \mathrm{ano}$, distribuída em, no mínimo, 104 dias de chuva (Estação de Ponta Grossa). Estas áreas estão inseridas no domínio dos Campos Gerais do Paraná, onde as estepes são marcadamente intercaladas por capões de floresta com araucária (floresta ombrófila mista - FOM) (Maack 2002).

Em direção à jusante do rio (Fig. 1), as oito áreas de estudo seguintes (10-19) pertencem à região de transição entre os tipos climáticos $\mathrm{Cfb}$ e Cfa (IAPAR 2008), que se sucedem ao longo do curso do rio. Nessa região, a precipitação média anual foi $1.602 \mathrm{~mm} / \mathrm{ano}$, distribuída em, no mínimo, 115 dias de chuva; a temperatura média do mês mais frio foi $10,9^{\circ} \mathrm{C}$ e do mês mais quente de $24^{\circ} \mathrm{C}$ (Estação de Telêmaco Borba). A vegetação deste trecho é ecotonal, representada pela floresta ombrófila mista com espécies típicas da floresta estacional semidecidual (FES), além dos fragmentos de savana.

Finalmente, o terceiro segmento do rio (Fig. 1), que abrange as seis áreas restantes em direção à foz (20-23), está inserido em clima enquadrado como Cfa, subtropical, com temperatura média do mês mais frio de $15,4^{\circ} \mathrm{C}$ e do mês mais quente $27,1^{\circ} \mathrm{C}$, verões quentes e geadas pouco freqüentes. Nesta região existe uma tendência de concentração das chuvas no verão, contudo sem estação seca definida. A precipitação média anual é de $1.531 \mathrm{~mm} / \mathrm{ano}$, distribuída em, no mínimo, 94 dias de chuva (Estação de Ibiporã). A vegetação está sob domínio da FES. 


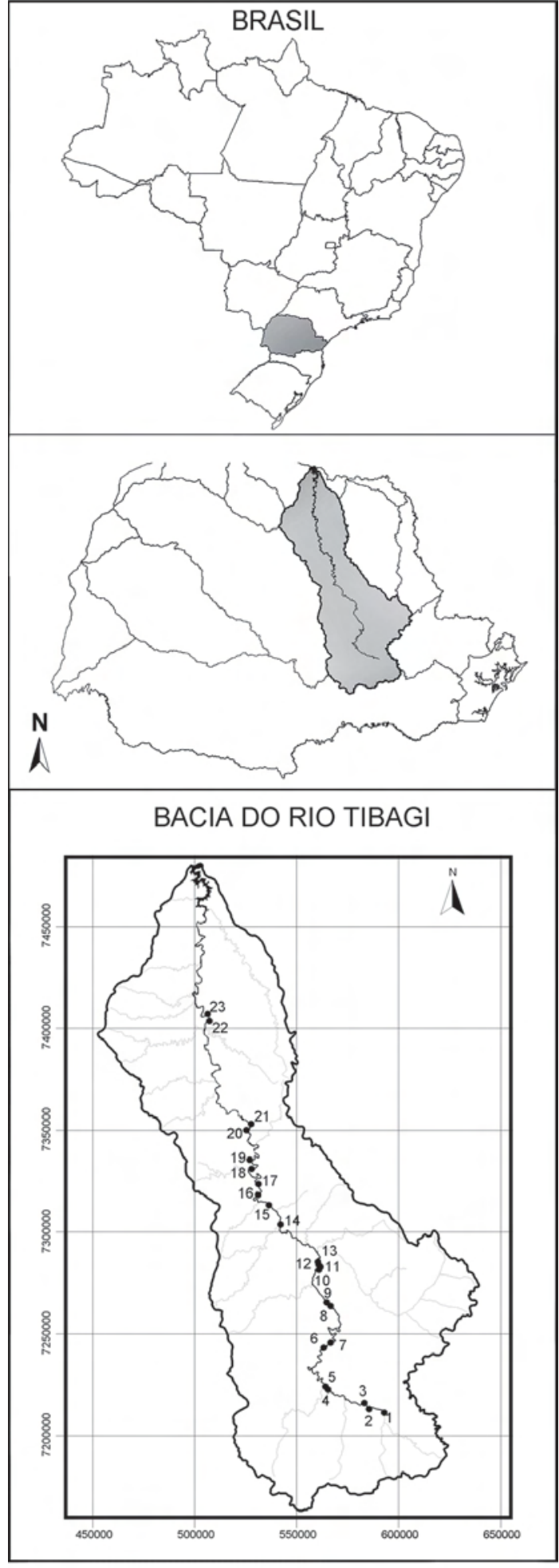

Figura 1 - Localização das áreas de estudo (1-23) ao longo do rio Tibagi, Paraná.

Figure 1 - Localization of study areas (1-23) along the Tibagi River, Paraná.
Ao longo de todo o rio Tibagi, é evidente a intervenção antrópica nas florestas. Nas áreas com planícies mais extensas, como aquelas próximas ao município de Ponta Grossa, a degradação da vegetação é maior, o que propiciou o intenso desenvolvimento de Guadua aff. paraguayana Döll, uma espécie nativa de bambu (Poaceae: Bambusoideae) extremamente agressiva e oportunista. Nas áreas de acesso mais difícil, como próximas da cabeceira do rio, além daquelas preservadas por empresa privada, especificamente no município de Telêmaco Borba, as florestas apresentam o melhor estado de conservação.

\section{Procedimento amostral}

As coletas dos epífitos vasculares foram realizadas em 23 áreas de estudo (Fig. 1), através do método do caminhamento (Filgueiras et al. 1994), incluindo somente paisagens caracterizadas, através de geomorfologia e solos, como pertencentes ao ambiente de planície. O deslocamento abrangeu, em média, dois hectares em cada área, totalizando, aproximadamente, 46 hectares distribuídos ao longo do rio Tibagi. Em campo, quando necessário, a visualização dos epífitos foi realizada com binóculo $(7 \times 35)$, e a coleta, com utilização de técnicas de escalada simples ou com equipamentos adaptados de montanhismo. Indivíduos estéreis, principalmente da família Orchidaceae, foram coletados para cultivo e posterior identificação.

A identificação das espécies foi baseada em literatura, no estudo de material herborizado e com auxílio de especialistas. Os nomes científicos foram verificados em The International Plant Names Index (IPNI 2009). O material-testemunho foi depositado no herbário do Departamento de Botânica (UPCB) da Universidade Federal do Paraná.

\section{Caracterização das plantas epifíticas}

As espécies epifíticas registradas ao longo do rio Tibagi foram classificadas de acordo com sua relação com os forófitos em cinco grupos ecológicos de plantas autótrofas, baseando-se em Benzing (1990). Holoepífitos característicos (HLC) são as espécies que passam todo o seu ciclo de vida sobre outras plantas; holoepífitos facultativos (HLF) são aquelas plantas que, em uma mesma comunidade, vivem tanto como epífitos quanto como rupícolas ou terrícolas; holoepífitos acidentais (HLA) são as que geralmente vivem como rupícolas ou terrícolas, mas são registradas ocasionalmente em ambiente epifítico. Os hemiepífitos primários (HMP) germinam sobre outras plantas e depois estabelecem contato 
com o solo e os hemiepífitos secundários (HMS) germinam no solo e depois criam contato com o forófito, eliminando a porção basal do sistema caulinar e/ou radicular.

Os epífitos também foram qualificados quanto ao grupo sucessional em que se enquadram nas áreas estudadas, à exceção dos holoepífitos acidentais e aqueles observados poucas vezes em campo. Foram enquadradas como espécies que ocupam o substrato em momentos iniciais da sucessão, de crescimento rápido e adaptadas a ambientes de alta luminosidade e grande amplitude térmica (pioneiras), ou como espécies que ocorrem em florestas em estágio adiantado de recuperação ou conservação e toleram condições de pleno sombreamento (avançadas) ou, ainda, como aquelas consideradas intermediárias nesse processo (secundárias).

\section{Análise dos dados}

A similaridade entre as comunidades de epífitos, registradas nas 23 áreas de estudo distribuídas ao longo do rio, foi calculada através do índice de Jaccard e seus resultados utilizados para confeccionar o algoritmo de agrupamento (método de Ward), elaborado com base na metodologia hierárquica-aglomerativa das médias das distâncias.

\section{Resultados e Discussão}

Ao longo do rio Tibagi foram registradas 47 espécies de pteridófitas e 141 angiospermas, totalizando 188 espécies de epífitos vasculares (ver Apêncide na versão eletrônica deste artigo). Destas, Begonia cucullata (Begoniaceae), Impatiens walleriana (Balsaminaceae) e Tradescantia zebrina (Commelinaceae) são espécies exóticas, sendo as duas últimas consideradas invasoras (I3N - Brasil 2009).

Este número de espécies é considerado elevado, o que é atribuído à heterogeneidade e complexidade ambiental das diversas regiões do rio, além do diâmetro máximo dos indivíduos arbóreos (Bonnet et al. 2010a). Considerando apenas a família Bromeliaceae, o número de espécies (22) supera aquele registrado em longa extensão de planícies do rio Iguaçu (Bonnet et al. 2010b), assim como o obtido em floresta ripária da Estação Ecológica JuréiaMartins (Araújo et al. 2004), área de floresta ombrófila densa (FOD), formação vegetacional esta considerada como detentora de máxima diversidade epifítica (Gentry \& Dodson 1987).

Orchidaceae, Polypodiaceae, Bromeliaceae, Piperaceae e Cactaceae foram as famílias que apresentaram maior número de representantes (ver
Apêncide na versão eletrônica deste artigo). No Paraná, este conjunto de famílias é modificado na sua composição apenas na FOD, onde Cactaceae e Piperaceae perdem a representatividade para famílias como Araceae e Hymenophyllaceae (Schütz-Gatti 2000; Breier 2005; Kersten \& Silva 2006), fato provavelmente relacionado à maior umidade atmosférica disponível naquela formação vegetacional (Gentry \& Dodson 1987; Waechter 1992).

As famílias que apresentaram apenas uma espécie foram Myrsinaceae, Monimiaceae, Myrtaceae, Schizaeaceae e Thelypteridaceae, todas representadas por plantas terrestres com ocorrência acidental no ambiente epifítico (ver Apêncide na versão eletrônica deste artigo), além de Dryopteridaceae, Gesneriaceae e Balsaminaceae, esta última representada pela espécie exótica Impatiens walleriana.

Quatro espécies constam na lista vermelha de plantas ameaçadas de extinção do Paraná, todas da família Orchidaceae: Sophronitis cernua e Isabelia virginalis em perigo, Baptistonia lietzei como vulnerável e Anathallis obovata, considerada rara (Hatschbach \& Ziller 1995). Estes dados remetem à importância da preservação efetiva dos ecossistemas fluviais, alvos comuns da degradação principalmente pela supressão dos remanescentes florestais e pela presença do gado.

A maior parte das espécies é estritamente holoepífita (73\%), seguida por holoepífitas acidentais (14\%), facultativas (10\%), hemiepífitas primárias (2\%)e apenas uma hemiepífita secundária. O predomínio de holoepífitos é resultado comum e esperado, tendo sido obtido em levantamentos no Rio Grande do Sul (Waechter 1992; Gonçalves \& Waechter 2003; Rogalski \&Zanin 2003) e no Paraná(Borgo \& Silva 2003; Kersten \& Kunyioshi 2006, Bonnet et al. 2009). Essas espécies são, de modo geral, as mais bem adaptadas ao modo de vida epifítico, apresentando características anatômicas, morfológicas e fisiológicas específicas para sobrevivência nestes ambientes, como cisternas, suculência ou tricomas para absorção de nutrientes e umidade por deposição aérea (Benzing 1990).

Os holoepífitos acidentais estabelecem-se casualmente em locais de acúmulo de matéria orgânica, como forquilhas, ocos ou grandes ramos de árvores, sendo comumente compostas por espécies terrestres. Ao longo do rio Tibagi, 44\% das famílias foram representadas unicamente por epífitos pertencentes a esta categoria (ver Apêncide na versão eletrônica deste artigo), incluindo espécies tipicamente arbóreas, como Myrsine coriacea e Myrciaria tenella, e herbáceas terrestres, como Tradescantia spp. e Selaginella spp. 
O grupo dos holoepífitos facultativos foi principalmente composto por piperáceas (ver Apêncide na versão eletrônica deste artigo), que foram registradas comumente na base dos fustes dos forófitos, como também sobre as rochas das margens formadas por depósitos de matacões de diversos tamanhos. As bromeliáceas Aechmea distichantha, A. bromeliifolia, Canistrum cyathiforme e Vriesea friburgensis foram observadas no ambiente epifítico, com maior freqüência, mas também sobre rochas e sobre Neossolos Flúvicos e Espodossolos Humilúvicos, de textura arenosa. Solos com textura arenosa possibilitam o rápido escoamento da água, evitando o encharcamento e contato excessivo da planta com a água. Algumas bromeliáceas, como Vriesea gigantea e Nidularium procerum, também registradas nas margens do rio Tibagi (ver Apêncide na versão eletrônica deste artigo) são citadas, em outras regiões geográficas, como ocorrendo em solos de restinga (Breier 2005) e solos com alta saturação hídrica da FOD (Freitas et al. 2003).

Os hemiepífitos pertencem às famílias Araceae, Blechnaceae e Moraceae, as duas últimas com distribuição mais restrita, apenas no ecótono e na floresta estacional semidecidual (FES) (ver Apêncide na versão eletrônica deste artigo). Estas três famílias possuem, comumente, representantes hemiepifíticos e foram observados nas planícies costeiras do Rio Grande do Sul (Waechter 1992), na restinga do litoral do estado de São Paulo (Breier 2005), na FOD do litoral do Paraná (Schütz-Gatti 2000), assim como na floresta ombrófila mista (FOM) do mesmo estado (Kersten \& Kunyioshi 2006; Bonnet et al. 2009).

Considerando a distribuição espacial dos epífitos ao longo do rio, maior riqueza de espécies foi registrada na região do ecótono, que representa a transição entre o domínio das unidades vegetacionais existentes ao longo do rio Tibagi - FOM e FES. Um total de 143 espécies foi registrado no ecótono (ver Apêncide na versão eletrônica deste artigo), enquanto 78 espécies ocorreram na região da FOM 63 espécies formaram o grupo de ocorrência da FES. Esta distribuição das espécies está de acordo com as maiores riquezas registradas no trecho entre as áreas 10-19 (Tab. 1), com vegetação de ecótono, onde foram observadas, em média, aproximadamente 47 espécies epifíticas em cada floresta estudada.

Tabela 1 - Áreas de estudo ao longo do rio Tibagi, com respectivas altitudes, tipos climáticos e vegetacionais, número total de famílias (Fam), gêneros (Gen) e espécies epifíticas (Esp).

Table 1 - Study areas along Tibagi River, with altitudes, climatic and vegetacional types, family (Fam), genera (Gen) and species (Esp) totals.

\begin{tabular}{ccccccc}
\hline Áreas & Altitude $(\mathbf{m})$ & Clima & Vegetação & Fam & Gen & Esp \\
\hline 1 & 1100 & Cfb & FOM & 8 & 17 & 29 \\
2 & 940 & Cfb & FOM & 9 & 26 & 44 \\
3 & 930 & Cfb & FOM & 12 & 24 & 31 \\
4 & 780 & Cfb & FOM & 6 & 17 & 25 \\
5 & 780 & Cfb & FOM & 5 & 14 & 22 \\
6 & 775 & Cfb & FOM & 4 & 10 & 14 \\
7 & 775 & Cfb & FOM & 6 & 15 & 21 \\
8 & 770 & Cfb & FOM & 7 & 22 & 34 \\
9 & 770 & Cfb & FOM & 6 & 14 & 20 \\
10 & 720 & Cfb/Cfa & Ecótono & 12 & 31 & 50 \\
11 & 712 & Cfb/Cfa & Ecótono & 8 & 25 & 37 \\
12 & 712 & Cfb/Cfa & Ecótono & 9 & 32 & 55 \\
13 & 700 & Cfb/Cfa & Ecótono & 9 & 19 & 29 \\
14 & 670 & Cfb/Cfa & Ecótono & 13 & 35 & 58 \\
15 & 630 & Cfb/Cfa & Ecótono & 17 & 38 & 56 \\
16 & 580 & Cfb/Cfa & Ecótono & 8 & 26 & 35 \\
17 & 580 & Cfb/Cfa & Ecótono & 10 & 28 & 44 \\
18 & 550 & Cfa & FES & 9 & 30 & 57 \\
19 & 520 & Cfa & FES & 11 & 31 & 47 \\
20 & 430 & Cfa & FES & 9 & 19 & 32 \\
21 & 430 & Cfa & FES & 12 & 26 & 31 \\
22 & 340 & Cfa & FES & 9 & 28 & 39 \\
23 & 340 & Cfa & FES & 3 & 5 & 7 \\
\hline
\end{tabular}


O número de espécies de ocorrência exclusiva também foi mais alto no ecótono (71), do que na FOM (28) e na FES (17). Maior riqueza de epífitos em região de ecótono também foi constatada no alto rio Iguaçu, PR, na zona de contato entre FOD e FOM em comparação com áreas sob domínio pleno da FOM (Kersten 2006).

Neste estudo, a região de ecótono foi definida considerando a vegetação arbórea, pois, de montante para jusante do rio, as florestas sob domínio da FOM vão sendo fortemente influenciadas por elementos da FES, além de encraves de savana (Hatschbach \& Ziller 1995). A elevada riqueza epifítica neste trecho do rio, associada ao grande número de espécies exclusivas desta unidade, deve-se, provavelmente, ao contato entre as unidades fitogeográficas (FOM, FES e savana), além do bom estado de conservação destas florestas integradas em longas faixas de vegetação fluvial. Bonnet et al. (2010a) apontam o diâmetro máximo dos indivíduos arbóreos como fator ampliador da diversidade alfa de epífitos no rio Tibagi. Destaca-se também, neste trecho do rio, a maior umidade disponibilizada para os epífitos pela existência de ressaltos topográficos na forma de corredeiras e cachoeiras no rio. Eles são, geralmente, originados por diques de diabásio que cruzam o canal transversalmente e produzem forte aspersão e vaporização de água na região circunvizinha.

Segundo Ab'Sáber \& Marigo (2006), as faixas de transição podem apresentar, além de representações de elementos fitogeográficos das unidades de contato, elementos que nada têm a ver com as duas unidades principais. Neste sentido, registrou-se a ocorrência de Nidularium procerum e Vriesea flava (Bromeliaceae), citadas como de ocorrência somente na FOD do estado do Paraná (Tardivo 1995; Costa et al. 2004). Azevedo \& Vieira (2008), nesta mesma região, obteve resultado semelhante com espécies arbustivas, até então registradas apenas para a FOD do Paraná. Neste sentido, pode-se afirmar que estas espécies da FOD estão inseridas no ecótono aproveitando a transição climática ou, apenas, que a região de distribuição destas espécies é mais ampla do que até então registrado.

A singularidade das comunidades epifíticas do ecótono é reforçada pelo valor do índice de similaridade. Entre o ecótono e as duas unidades vegetacionais a similaridade calculada foi muito semelhante e pode ser considerada baixa (Fig. 2), apresentando 49 espécies em comum com a FOM $(\mathrm{J}=0,2848)$ e 45 com a FES $(\mathrm{J}=0,2795)$. Similaridades tão próximas ratificam a posição transicional do ecótono ao longo do rio; o baixo valor vem ao encontro do padrão singular apontado por Ab'Sáber \& Marigo (2006) para as faixas de transição, além do bom estado de conservação das florestas neste trecho do rio, com indivíduos arbóreos de grandes diâmetros (Bonnet et al. 2010a). Destaca-se, portanto, a importância das comunidades epifíticas de cada trecho do rio e da preservação dos ecossistemas florestais fluviais que suportam floras tão diferenciadas.

Entre FOM e FES o número de espécies em comum foi ainda menor (23), assim como a similaridade $(\mathrm{J}=0,1949)$, refletindo a distância geográfica entre as áreas e, provavelmente, o elevado grau de desmatamento e degradação das florestas fluviais.

A maioria dos epífitos exclusivos de uma unidade vegetacional pertence à família Orchidaceae (ver Apêncide na versão eletrônica deste artigo). Este resultado, assim como a predominância desta família sobre as demais, estão relacionados com a sua elevada riqueza, estimada por Judd et al. (2009) em 19.500 espécies, distribuídas em 788 gêneros. Sua ocorrência disjunta no gradiente linear das florestas das margens do rio Tibagi, com pouca sobreposição de áreas de ocorrência, está de acordo com dados da literatura (Küper et al. 2004), que relaciona sua elevada plasticidade evolutiva em populações pequenas e isoladas em diferentes regiões geográficas (Benzing 1990). No rio Tibagi, deve-se ainda considerar a forte fragmentação

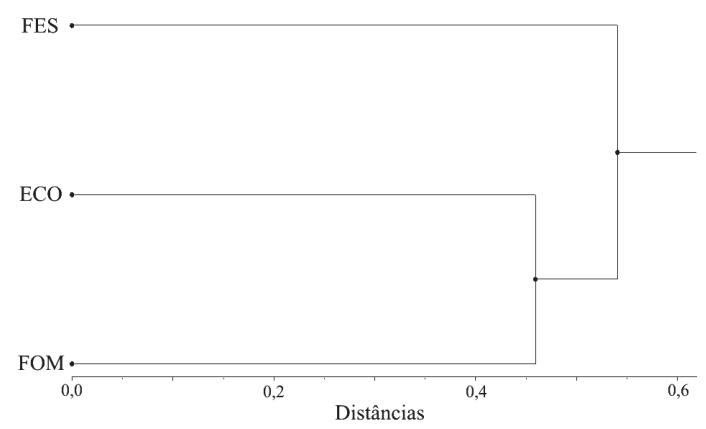

Figura 2 - Dendrograma das unidades vegetacionais que acompanham o rio Tibagi, baseado na similaridade dos epífitos vasculares. FOM = floresta ombrófila mista; $\mathrm{ECO}=$ ecótono $; \mathrm{FES}=$ floresta estacional semidecidual. Figure 2 - Dendrogram reporting relationships among vegetacional units along Tibagi River, based on the similarity of vascular epiphytes. FOM = mixed ombrophylous forest; $\mathrm{ECO}-$ ecotone; FES $=$ seasonal semideciduous forest. 
dos habitats, além da necessidade de estudos sistemáticos dos ambientes e seus componentes, incluindo aí a flora epifítica.

As espécies das famílias com distribuição mais ampla, Bromeliaceae, Polypodiaceae e Cactaceae são, na sua maioria, pertencentes ao grupo dos epífitos enquadrados como pioneiros na sucessão (ver Apêncide na versão eletrônica deste artigo). As espécies pioneiras, como Tillandsia tenuifolia, Rhipsalis cereuscula, Microgramma squamulosa, Pleopeltis hirsutissima e P. pleopeltifolia foram registradas em outras regiões do estado do Paraná nestas classificação sucessional (Kersten \& Kuniyoshi 2009; Bonnet et al. 2009), e caracterizamse por apresentar resistência a condições de elevada amplitude lumínica e térmica. Dentre as espécies adaptadas, as bromeliáceas consideradas atmosféricas possuem escamas foliares, ou tricomas, cobrindo as suas folhas, com a função de absorção de nutrientes e umidade por via atmosférica e rápida capacidade de reidratação (Benzing et al. 1978). Essa cobertura densa de tricomas delineia a tendência de plantas, como Tillandsia tenuifolia e T. recurvata, de ocorrerem em locais mais expostos das copas, quando em regiões úmidas, ou em regiões áridas (Sudgen 1981). As espécies poiquilohídricas, como Pleopeltis hirsutissima e $P$. pleopeltifolia, perdem água rapidamente em períodos de seca, mas são tolerantes à dessecação e retornam à forma e atividades com o aumento da umidade (Benzing 1990). Outras espécies são decíduas, perdendo suas folhas nos períodos mais secos para evitar a dessecação e morte da planta (Benzing 1990), como Serpocaulon catharinae. As espécies epifíticas pioneiras na sucessão, de modo geral, ocorrem tanto nas comunidades de florestas com maior intervenção antrópica como naquelas mais conservadas, principalmente sobre os forófitos da margem do rio e nas porções mais altas da copa, ambos segmentos das florestas fluviais onde a intensidade lumínicaémaior.

As espécies secundárias exigem mais umidade e toleram maior sombreamento no ambiente florestal, sendo representadas por exemplares de várias famílias epifíticas, como Araceae (Philodendron loefgrenii e $P$. bipinnatifidum), Polypodiaceae (Pecluma sicca e $P$. pectinatiformis), Piperaceae (Peperomia delicatula e $P$. rotundifolia) e Orchidaceae (Leptotes unicolor L Lophiaris pumila).

Nas florestas mais avançadas na sucessão/ conservadas, foram observadas, concomitante à presença de pioneiras e secundárias, os epífitos avançados na sucessão, colonizando os forófitos em locais mais sombreados e com maior umidade relativa. Estes epífitos apresentam distribuição mais restrita ao longo do rio, o que está relacionado com o nível de intervenção antrópica. Dentre elas, podese eleger um grupo de espécies indicadoras de ambientes mais bem conservados das margens do rio Tibagi, como Microgramma lindbergii (Polypodiaceae), Peperomia martiana e $P$. alata (Piperaceae), Sinningia douglasii (Gesneriaceae), Hatiora salicornioides (Cactaceae), Asplenium serra (Aspleniaceae), Isabelia pulchella, I. virginalis e Isochilus linearis (Orchidaceae). As bromeliáceas-tanque Canistrum cyathiforme, Nidularium procerum e Vriesea flava apresentam distribuição restrita a ambientes em melhor estado de conservação, o que está de acordo com o aumento de plantas formadoras de tanque em momentos tardios na sucessão epifítica e em ambientes mais conservados, como demonstrado em Santa Catarina para florestas de encosta (Bonnet \& Queiroz 2006).

\section{Agradecimentos}

Aos especialistas Americo D. Neto, Cássia Sakuragui, Dalton H. Baptista, Jorge L. Waechter, Marcus A.N. Coelho, Marilia Borgo, Paulo H.L. Evangelista, Rosângela C. Tardivo e equipe do Museu Botânico Municipal, sem os quais este trabalho não teria sido possível; ao CNPq, o apoio financeiro ao projeto e bolsa de estudos; à Klabin S.A. e à Embrapa Florestas, o suporte em campo e ao IAPAR, os dados climáticos.

\section{Referências}

Ab'Sáber, A. \& Marigo, L.C. 2006. Ecossistemas do Brasil. Metalivros. São Paulo, 299p.

Araújo, A.C.; Fischer, E.; Sazima \& M. 2004. As bromélias na região do rio Verde. In: Marques, O.A.V. \& Duleba, W. (eds). Estação Ecológica Juréia-Itatins. Ambiente físico, flora e fauna. Holos, Ribeirão Preto Pp. 162-171.

Azevedo, T.I.N. \& Vieira, A.O.S. 2008. As plantas herbáceas e arbustivas da bacia do Ribeirão Varanal. In: Bennemann, S.T.; Shibatta, O.A. \& Vieira, A.O.S. (eds). A flora e a fauna do Ribeirão Varanal. Eduel, Londrina. Pp. 17-68.

Benzing, D.H. 1990. Vascular epiphytes. Cambridge University Press, New York, 354 p.

Benzing, D.H.; Seemann, J. \& Renfrow, A. 1978. The foliar epidermis in Tillandsioideae (Bromeliaceae) and its role in habitat selection. American Journal of Botany 65: 359-365.

Bonnet, A. \& Queiroz, M.H. 2006. Estratificação vertical de bromélias epifíticas em diferentes estádios sucessionais da floresta ombrófila densa, Ilha de Santa Catarina, Santa Catarina, Brasil. Revista Brasileira de Botânica 29: 217-228. 
Bonnet, A.; Curcio, G.R.; Lavoranti, O.J. \& Galvão, F. 2010a. Relações de epífitos vasculares com fatores ambientais nas florestas do Rio Tibagi, Paraná, Brasil. Biotemas 23: 37-47.

Bonnet, A.; Curcio, G.R.; Galvão, F.; Lavoranti, O.J., Barddal, M. \& Roderjan, C.V. 2010b. Relações de bromeliáceas epifíticas com fatores ambientais em planícies de inundação do rio Iguaçu, Paraná, Brasil. Floresta 40: 193-208.

Bonnet, A.; Lavoranti, O.J. \& Curcio, G.R. 2009. Epífitos vasculares no Corredor de Biodiversidade Araucária, bacia do rio Iguaçu, Paraná, Brasil. Cadernos de Biodiversidade 6: 49-70.

Borgo, M. \& Silva, S.M. 2003. Epífitos vasculares em fragmentos de floresta ombrófila mista, Curitiba, Paraná, Brasil. Revista Brasileira de Botânica 26: 391-401.

Breier, T. B. 2005. O epifitismo vascular em florestas do sudeste do Brasil. Tese de Doutorado. Universidade Estadual de Campinas, Campinas. Pp. 1-139.

Costa, A.F.; Luther, H.E. \& Wanderley, M.G.L. 2004. A new species of Vriesea (Bromeliaceae) from the Atlantic Forest, Brazil. Novon 14: 36-39.

Dittrich, V.A.O.; Kozera, C. \& Silva, S.M. 1999. Levantamento florístico dos epífitos vasculares do Parque do Barigui, Curitiba, Paraná, Brasil. Iheringia série botânica 52: 11-21.

Filgueiras, T. S.; Nogueira, P. E.; Brochado, A.L. \& Guala II, G. F. 1994. Caminhamento: um método expedito para levantamentos florísticos qualitativos. Cadernos de Geociências 12: 39-43.

Fontoura, T.; Sylvestre, L.S.; Vaz, A.M.S. \& Vieira, C.M. 1997. Epífitos vasculares, hemiepífitos e hemiparasitas da Reserva Ecológica de Macaé de Cima. In: Lima, H.C. \& Guedes-Bruni, R.R. (eds.). Serra de Macaé de Cima: diversidade florística e conservação da Mata Atlântica. Jardim Botânico do Rio de Janeiro, Rio de Janeiro. Pp. 89-101.

Freitas, C.A.; Scarano, F.R. \& Blesboer, D.D. 2003. Morphological variation on two facultative epiphytic bromeliads growing on the floor of a swamp forest. Biotropica 35: 546-550.

Gentry, A.H. \& Dodson, C.H. 1987. Diversity and biogeography of neotropical vascular epiphytes. Annals of Missouri Botanical Garden 74: 205-233.

Giongo, C. \& Waechter, J.L. 2004. Composição florística e estrutura comunitária de epífitos vasculares em uma floresta de galeria na Depressão Central do Rio Grande do Sul. Revista Brasileira de Botânica 27: 563-572.

Gonçalves, C.N. \& Waechter, J.L. 2003. Aspectos florísticos e ecológicos de epífitos vasculares sobre figueiras isoladas no norte da planície costeira do Rio Grande do Sul. Acta Botânica Brasílica 17: 89-100.

Hatschbach, G.G. \& Ziller, S.R. 1995. Lista vermelha de plantas ameaçadas de extinção no estado do Paraná. Sema/GTZ, Curitiba. 139p.
IAPAR - Instituto Agronômico do Paraná. 2009. Disponível em <http://www.iapar.br>. Acesso em $13 \mathrm{dez} 2008$.

IPNI - International Plant Names Index. 2009. Disponível em <http://www.ipni.org>. Acesso em 15 Fev 2009.

I3N. 2009. Base de dados sobre espécies exóticas invasoras. Disponível em <http://www.institutohorus.org.br $>$. Acesso em 8 Jan 2009.

Judd, W.S.; Campbell, C.S.; Kellogg, E.A.; Stevens, P.F \& Donoghue, M.J. 2009. Sistemática vegetal - um enfoque filogenético. $3^{\mathrm{a}}$ ed. Artmed, Porto Alegre. 632p.

Kersten, R.A. 2006. Epifitismo vascular na bacia do alto Iguaçu. Tese de Doutorado. Universidade Federal do Paraná, Curitiba. $218 f$.

Kersten, R.A. \& Silva, S.M. 2006. The floristic compositions of vascular epiphytes of a seasonally inundated forest on the coastal plain of Ilha do Mel Island, Brazil. Revista de Biologia Tropical 54: 935-942.

Kersten, R.A. \& Kunyioshi, Y.S. 2006. Epífitos vasculares na bacia do alto Iguaçu, Paraná, Brasil - composição florística. Estudos de Biologia 28: 55-71.

Kersten, R.A. \& Kunyioshi, Y.S. 2009. Conservação das florestas na bacia do alto Iguaçu, Paraná avaliação da comunidade de epífitas vasculares em diferentes estágios serais. Floresta 39: 51-66.

Küper, W.; Kreft, H.; Nieder, J.; Koster, N.; Barthlott, W. 2004. Large-scale diversity patterns of vascular epiphytes in Neotropical montane rain forests. Journal of Biogeography 31: 1477-1487.

Maack, R. 2002. Geografia física do estado do Paraná. $3^{\text {a }}$ ed. Imprensa Oficial, Curitiba, 438p.

Rogalski, J.M. \& Zanin, E.M. 2003. Composição florística de epífitos vasculares no estreito de Augusto César, floresta estacional decidual do Rio Uruguai, RS, Brasil. Revista Brasileira de Botânica 26: 551-556.

Silva, S.M.; Britez, R.M.; Souza, W.S. de \& Motta, J.T.W. 1997. Levantamento florístico em área de várzea do rio Iguaçu, São Mateus do Sul, PR, Brasil. Arquivos de Biologia e Tecnologia 40: 903-913.

Schütz-Gatti, A.L. 2000. O componente epifítico vascular na Reserva Natural de Salto Morato, Guaraqueçaba - PR. Dissertação de Mestrado. Universidade Federal do Paraná, Curitiba. 93p.

Sudgen, A.M. 1981. Aspects of the ecology of vascular epiphytes in two Colombian cloud forests. II. Habitat preferences of Bromeliaceae in the Serrania de Macuira. Selbyana 5: 264-273.

Tardivo, R.C. 1995. Os gêneros Nidularium Lemaire \& Canistrum E. Morren (Bromeliaceae) no Estado do Paraná. Dissertação de Mestrado. Universidade Federal do Paraná, Curitiba. 160p.

Waechter, J.L. 1992. O epifitismo vascular na planície costeira do Rio Grande do Sul. Tese de Doutorado. Universidade Federal de São Carlos, São Carlos. 163p. 